\title{
Coastal flooding of urban areas by overtopping: dynamic modelling application to the Johanna storm (2008) in Gâvres (France)
}

\author{
S. Le Roy ${ }^{1}$, R. Pedreros ${ }^{1}$, C. André ${ }^{1,2}$, F. Paris ${ }^{1}$, S. Lecacheux ${ }^{1}$, F. Marche ${ }^{3}$, and C. Vinchon ${ }^{1}$ \\ ${ }^{1}$ BRGM - 3, avenue Claude Guillemin, BP 36009, 45060 Orléans CEDEX 2, France \\ ${ }^{2}$ LETG-Brest Géomer, UMR 6554 CNRS, University of Western Brittany, European Institute for Marine Sciences, \\ Place Nicolas Copernic, 29280, Plouzané, France \\ ${ }^{3}$ I3M, University of Montpellier 2 and INRIA LEMON, CC 051, 34000 Montpellier, France
}

Correspondence to: S. Le Roy (s.leroy@brgm.fr)

Received: 11 April 2014 - Published in Nat. Hazards Earth Syst. Sci. Discuss.: 4 August 2014

Revised: 12 May 2015 - Accepted: 14 May 2015 - Published: 11 November 2015

\begin{abstract}
Recent dramatic events have allowed significant progress to be achieved in coastal flood modelling over recent years. Classical approaches generally estimate wave overtopping by means of empirical formulas or 1-D simulations, and the flood is simulated on a DTM (digital terrain model), using soil roughness to characterize land use. The limits of these methods are typically linked to the accuracy of overtopping estimation (spatial and temporal distribution) and to the reliability of the results in urban areas, which are places where the assets are the most crucial.

This paper intends to propose and apply a methodology to simulate simultaneously wave overtopping and the resulting flood in an urban area at a very high resolution. This type of 2-D simulation presents the advantage of allowing both the chronology of the storm and the particular effect of urban areas on the flows to be integrated. This methodology is based on a downscaling approach, from regional to local scales, using hydrodynamic simulations to characterize the sea level and the wave spectra. A time series is then generated including the evolutions of these two parameters, and imposed upon a time-dependent phase-resolving model to simulate the overtopping over the dike. The flood is dynamically simulated directly by this model: if the model uses adapted schemes (well balanced, shock capturing), the calculation can be led on a DEM (digital elevation model) that includes buildings and walls, thereby achieving a realistic representation of the urban areas.

This methodology has been applied to an actual event, the Johanna storm (10 March 2008) in Gâvres (South Brittany, in western France). The use of the SURF-WB model, a very sta-
\end{abstract}

ble time-dependent phase-resolving model using non-linear shallow water equations and well-balanced shock-capturing schemes, allowed simulating both the dynamics of the overtopping and the flooding in the urban area, taking into account buildings and streets thanks to a very high resolution $(1 \mathrm{~m})$. The results obtained proved to be very coherent with the available reports in terms of overtopping sectors, flooded area, water depths and chronology. This method makes it possible to estimate very precisely not only the overtopping flows, but also the main characteristics of flooding in a complex topography like an urban area, and indeed the hazard at a very high resolution (water depths and vertically integrated current speeds).

The comparison with a similar flooding simulation using a more classical approach (a digital terrain model with no buildings, and a representation of the urban area by an increased soil roughness) has allowed the advantages of an explicit representation of the buildings and the streets to be identified: if, in the studied case, the impact of the urbanization representation on water levels does indeed remain negligible, the flood dynamics and the current speeds can be considerably underestimated when no explicit representation of the buildings is provided, especially along the main streets. Moreover, on the seaside, recourse to a timedependent phase-resolving model using non-stationary conditions allows a better representation of the flows caused by overtopping.

Finally, this type of simulation is shown to be of value for hazard studies, thanks to the high level of accuracy of the results in urban areas where assets are concentrated. This 
methodology, although it is currently still quite difficult to implement and costly in terms of calculation time, can expect to be increasingly resorted to in years to come, thanks to the recent developments in wave models and to the increasing availability of LiDAR data.

\section{Introduction}

Recent events have highlighted the exposure of human society to coastal flooding caused by cyclones or storm events. For example, Hurricane Katrina (2005) in Louisiana, Xynthia storm (2010) in France or Hurricane Sandy (2012) in the New York metro area left, in their wake, thousands of victims and billions of dollars' worth of damage to the built environment and economic losses, largely the result of marine flooding. Much recent effort has been devoted to improving numerical simulations of coastal flooding in order to ensure communities have access to precise and relevant knowledge about past and future hazards and to extrapolate from these the damage they may need to contend with in the future.

Modelling flood dynamics in urban areas is a subject which was addressed quite recently; considerable headway has indeed been made in the field over the past decade, due to the need for fluvial flood simulations. Most commonly used methods developed to represent floods in urban areas rely on the same approach as for rural areas: the impact of the built environment is integrated by assigning high roughness coefficients at the scale of the urban area or of the building aggregates (for example, Gallegos et al., 2009, on a dam-failure case). Nevertheless, these methods do not enable a realistic representation of the flows in these zones of particular interest to be obtained.

The development of airborne scanning laser altimetry (LiDAR) has allowed floods to be simulated at a very high resolution, including urban areas, through different representations of individual buildings (inclusion as blocks in the topography, external walls, porosity, raised roughness, etc.). Schubert et al. $(2008,2012)$ tested different types of representation for the buildings (hole in the calculation grid, block, higher friction, porosity) with the BreZo model (Begnudelli et al., 2008), which uses unstructured meshes. The authors conclude that all of these methods are able to represent the flood extension accurately provided the resolution is high enough but that the flow velocities are harder to predict and more dependent on the method.

The resolution required must correlate with the sizes of buildings and streets. Neal et al. (2009) compared measurements taken after the 2005 Carlisle flood (UK) to simulations made with the LISFLOOD-FP model (Bates and De Roo, 2000; Bates et al., 2010) on a $25 \mathrm{~m}$ resolution DTM (digital terrain model) and DEM (digital elevation model). They conclude that at this relatively coarse resolution, it is better to use DTM than DEM to avoid water blockage by an ag- gregation of buildings. In order to estimate the appropriate resolution, Fewtrell et al. (2011) used terrestrial LiDAR data to simulate, with the same model, the flood that affected Alcester (UK) in 2007, compared the simulation results at very high resolutions $(0.5,1,2$ and $5 \mathrm{~m})$, and concluded that, in this case, there is a gap in terms of performance between 2 and $5 \mathrm{~m}$ resolutions. However, the critical resolution does remain specific to the numerical schemes of the model and to the site (width of the streets and of the buildings, orientation of the streets compared to the numerical schemes, etc.).

Coastal flooding brings up another question about the dynamics of incoming water, depending on the state of the sea. Two main processes of coastal flooding are typically distinguished: the general overflowing (elevation of the sea level above protective structures or natural defences, caused by the combined effects of the tide, storm surge, and occasionally the wave setup) and the wave overtopping (passing of the waves above protective structures or natural defences). These two mechanisms are often coupled with variable contributions and with a particular interaction caused by potential damage to the protections by wave shocks.

Urban coastal floods continue to be less frequently studied than continental flooding. Existing coastal flooding simulations usually concern generalized overflowing for the most part, for which broader areas are affected and waves can be neglected. The most common approach consists of imposing sea level (taking into account tide, storm surge and occasionally wave setup) on a coarse DTM, with particular attention devoted to coastal defences. Urbanization is then represented by introducing a higher roughness coefficient, as for continental flood simulations at large scales. The models used are generally "storage cell" models (for example Bates et al., 2005) and NLSW (Non Linear Shallow Water) equations models (for example Fortunato et al., 2013; Gallien et al., 2011). Other simplified methods that do not entail the use of actual simulations proper consist of using static or semi-static methods to estimate the extent of the flooded area (Breilh et al., 2013).

The problem of coastal flooding due to wave overtopping is as yet imperfectly resolved. Most of the studies described in the scientific literature call on empirical formulations to estimate overtopping over the defences, like the ones of EurOtop (Pullen et al., 2007). The flood simulation is then achieved via hydrodynamic models. Indeed, Smith et al. (2012) used the LISFLOOD-FP model on a $50 \mathrm{~m}$ resolution DTM, combined with roughness to represent soil use, to simulate a flood by combined surge and waves: the overtopping was represented by source cells where the overtopping rate had been estimated. On the site of Gâvres (South Brittany, in western France), studied hereinafter, Le Cornec and Peeters (2008) used the EurOtop formulas on four profiles to estimate overtopping flows, and then used a hydrodynamic model to simulate the flood.

Recent progress in numerical methods has materially improved the approaches available in terms of wave overtop- 
ping simulations, allowing time-dependent phase-resolving models to acquire the requisite reliability. These models commonly use vertical integrated approaches, using either Boussinesq equations (dispersive, adapted to offshore propagation) or non-linear shallow water (NLSW) equations (nondispersive, adapted to long waves).

Most of these recent models have adopted similar strategies to correctly represent the complex phenomenon of wave overtopping:

- Shock capturing schemes have been implemented to simulate the steep wavefront in the surf zone; they allow the models to deal with highly variable flows and to treat discontinuities in the flows. Initially used to deal with broken waves, shock capturing schemes have proven very useful to simulate flows in very complex topographies such as urban areas (this type of scheme is now used for continental flooding simulations as well).

- Well-balanced schemes were integrated to accommodate the sharp pressure gradients caused by steep slopes in the topography; these schemes, based on the equilibrium between source terms and velocity gradients, confer more stability to the model and allow it to converge towards an equilibrium state; here too, this characteristic developed for wave models has proven very convenient to simulate flows between buildings in urban areas.

- Wave breaking needs specific processing to characterize energy dissipation and wave behaviour before and after breaking. It generally requires the identification of the breaking zone (geometrical or dynamical criteria). Subsequently, several strategies are used: Boussinesq models add a dissipation term to characterize the loss of energy (for example Lynett, 2006, 2010), while shockcapturing NLSW models are able to represent the behaviour of breaking waves (Bonneton, 2007; Brocchini and Dodd, 2008; Kobayashi et al., 1989; Marche et al., 2007). Another robust and elegant solution consists in using Boussinesq equations offshore, then identifying the breaking point and switching to NLSW equations to represent broken waves. This approach is seeing increasing use (Tissier et al., 2012; Shi et al., 2012; McCabe et al., 2013; Tonelli and Petti, 2013), but it needs specific adaptations in terms of equations and numerical schemes (Bonneton et al., 2011; Lannes and Marche, 2014).

Currently, the operational use of these models is still limited mainly to 1-D simulations to estimate overtopping rates over coastal dikes (for example McCabe et al., 2013; TorresFreyermuth et al., 2012; Tissier et al., 2012; Lynett et al., 2010), or to 2-D simulations on experimental cases (for example, Shi et al., 2012; Zijlema et al., 2011). For example, Stansby et al. (2013) calculated an incoming discharge with

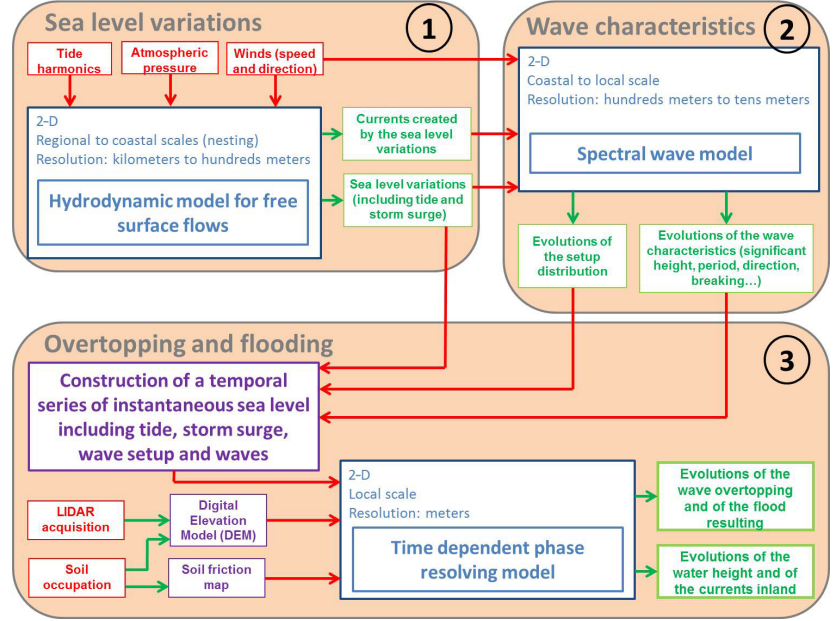

Figure 1. Modelling method proposed to simulate wave overtopping and associated flooding.

a 1-D Boussinesq-NLSW hybrid model, and injected them in a 2-D finite elements hydrodynamic model (DEM, spatial resolution varying from 50 to $1 \mathrm{~m}$ ) to simulate the associated flood in Walcott (UK). They showed that using instantaneous or averaged discharges can significantly impact the simulated water level.

Recent progresses in numerical modelling, together with the availability of very high resolution topographic data, now allows simulating both wave overtopping and coastal flooding as accurately and realistically as possible with a unique 2-D model.

The choice of the overtopping and flooding model depends on the constraints of the site being studied. These include more particularly the position of the forcing conditions (conditioned by the numerical and physical limits of the models), the tidal context (duration of wave overtopping generally controlled by the tide in macro-tidal context, so the model must be robust enough to allow an overall variation in sea level to be simulated) and the domain characteristics (wellparallelized models can counterbalance the lengthy computation time entailed when the area covered is extensive and the resolution needed is high).

The present paper proposes and applies a methodology to simulate coastal flooding by wave overtopping in an urban area at a very high resolution. A simulation of a flood event induced by overtopping during the Johanna storm (2008) in the village of Gâvres is conducted by implementing this methodology and validated by observations. This methodology can be adapted, or even simplified, to simulate coastal flooding due to generalized overflowing. 


\section{Modelling method}

The proposed modelling process to simulate coastal flooding caused by a storm at very high resolution in urban areas (but likewise valid for rural areas), includes non-stationary conditions to estimate as realistically as possible (spatial distribution of the overtopping, chronology, etc.) the water volume passing inland by wave overtopping and/or general overflowing. The overall method is illustrated in Fig. 1.

The method relies on prerequisite calculations at regional and local scales of the offshore characteristics of the storm; this downscaling approach is quite similar to the ones used by Pedreros et al. (2011) or Stansby et al. (2013), with a last step that aims to be more integrative and realistic:

- Fig. 1 (1): a hydrodynamic free-surface model is used at a regional scale to simulate the sea level variations caused by both tide and storm surge. Several nested grids can be used to obtain a satisfactory resolution around the studied area, according to the scale of phenomena addressed. Typical models that can be used for this step are barotropic hydrodynamic models.

- Fig. 1 (2): the waves are simulated by a spectral model that manages both generation by the wind and propagation of the waves. This simulation takes into account the evolutions of sea level and currents calculated in the previous simulation (1). Several nested grids are generally needed to achieve a sufficient resolution (a few metres or tens of metres) to account for the phenomena near the coast (especially wave breaking).

- Fig. 1 (3): the last step is the simulation of the wave overtopping and associated flood, performed at very high resolution. This simulation includes the previous results (sea level and wave characteristics) to represent the flood dynamics as realistically as possible. The use of an adapted model makes it possible to take land use into account, especially in urban areas (interactions between flows and buildings). This is carried out using a DEM, based on LiDAR acquisitions, with an adapted resolution (determined by the size of streets, walls, inter-building spaces, etc.).

The application of this methodology to the flood caused by the Johanna storm (2008) in the village of Gâvres is presented in the following paragraphs, with special attention devoted to the third phase, which is the most innovative.

\section{Application to the Johanna storm in Gâvres}

\subsection{Study area, actual event and earlier work}

The village of Gâvres is located on a small peninsula of South Brittany (France) adjoining the Lorient harbour exit. The site is exposed to a semi-diurnal macro-tidal context, with a maximum astronomic tidal range of $5.39 \mathrm{~m}$ (at PortLouis; SHOM, 2012). The village centre is directly exposed to the waves coming from the Bay of Biscay to the south, with a limited protection offered by Groix island, located more than $7 \mathrm{~km}$ to the south-west. Owing to its particular situation, Gâvres has suffered repeatedly from coastal flooding (1978, 2001, 2004, 2008, 2009, etc.), affecting mostly the lowest area, around the football pitch, that is known to be a former wetland that has been polderized and urbanized since the fifties (Cariolet, 2011). This topographic depression is protected from the sea by a dike at the top of the main beach, which culminates at about $4.1 \mathrm{~m}$ above the mean sea water level and which is topped by $0.8 \mathrm{~m}$ high wall.

The event studied in the present paper occurred on 10 March 2008, caused by the Johanna storm. This storm, described by Cariolet et al. (2010), struck Brittany and areas northwards; the trajectory of the depression passed over southern Ireland and England from west to east, with atmospheric pressures reaching $975 \mathrm{hPa}$ in extreme western Brittany, maximum winds of $150 \mathrm{~km} \mathrm{~h}^{-1}$ and significant wave heights exceeding $13 \mathrm{~m}$. The coincidence of the generated storm surge (between 0.7 and $0.8 \mathrm{~m}$ measured in South Brittany) with a period of spring tides caused considerable damage due to scattered coastal flooding extending from South Brittany to Normandy and Picardy (André et al., 2013; André, 2013).

In Gâvres, the two successive high tides of 10 March 2008 (05:11 and 17:22 in Port-Tudy ${ }^{1}$ ) led to wave overtopping over the dike of the main beach, partial destruction of the eastern part of the wall on the dike and subsequent flooding in the village, mostly during the morning high tide. Figure 2 illustrates the overall situation of Gâvres, and Fig. 3 presents the general phenomena in Gâvres, with overtopping waves coming from the south. According to witnesses (Le Cornec and Peeters, 2008), the lowest topographic point of the area was reached by water at about 05:00 and the level rose until approximately 06:00 to reach more than $1 \mathrm{~m}$ high (Cariolet, 2010). No available data enable us to estimate the duration of the overtopping and the evolution of the incoming flow rate during the storm.

Le Cornec and Peeters (2008) have applied a methodology developed and validated by Peeters et al. (2009) to simulate this event using a simulation of wave generation and propagation, by a spectral model (Mike $21 \mathrm{SW}$ ), some 1-D simulations of the wave climate propagation along four profiles, with a $1 \mathrm{~h}$ time step. This allowed the estimation of the wave characteristics on the dike (model LITPACK), an estimation of the hourly overtopping flows over the dike (on the four profiles) through EurOtop empirical formulas (Pullen et al., 2007), and finally a simulation of the flows with a hydrodynamic model (Mike $21 \mathrm{HD}$ ) at a $2.5 \mathrm{~m}$ resolution. Their results correspond closely to reports and measurements, de-

\footnotetext{
${ }^{1}$ In the remainder of this paper, all the indicated hours are UTC, for both the actual event and simulations.
} 


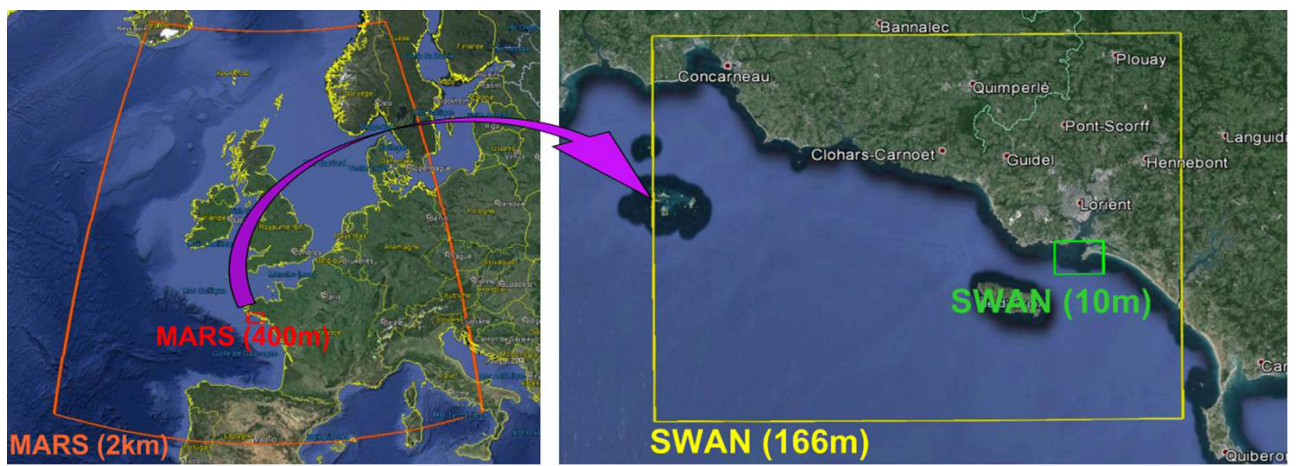

Figure 2. Location map of Gâvres, areas covered by the regional and coastal simulations (sea water level with MARS on the left, wave characteristics with SWAN on the right).

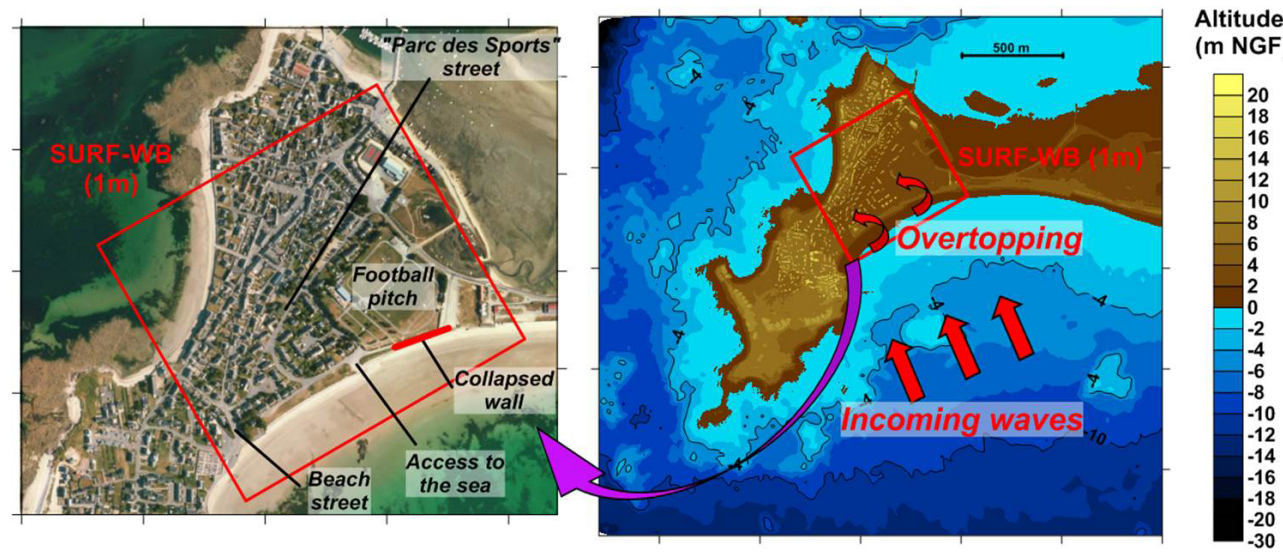

Figure 3. Area covered by the overtopping and flooding simulation: configuration of the site and main landmarks on the left, topography and bathymetry on the right.

spite a slight overestimation of the flood (in extension and water levels). The methodology proposed in the present paper aims, in particular, to improve the modelling of the overtopping processes.

\subsection{From the regional scale to the local scale}

\subsubsection{Modelling the sea level evolutions: tide and storm surge}

The simulation of the sea level evolutions has been conducted with the MARS model, developed by Lazure and Dumas (2008). The calculations were applied to two regular nested grids having resolutions of $2 \mathrm{~km}$ and $400 \mathrm{~m}$ respectively (the calculation domains are depicted in Fig. 2). The larger grid was used to calculate the atmospheric storm surge. On the nested grid, the tide was simulated by the forcing on the boundaries of the calculation domain of this storm surge combined with 143 tidal components supplied by SHOM (database CST France, Le Roy and Simon, 2003). To simulate the storm surge, the atmospheric conditions are derived from the CFSR-NOAA data set (Saha et al., 2010): winds and atmospheric pressure, available at a $0.5^{\circ}$ resolution, were exploited to calculate the non-stationary sea level over the whole studied area, and during a long enough period to attain an established situation. The results turn out to be very coherent with the observations available for the 10 March 2008 in terms of total sea level and of storm surge, especially in Port-Tudy (Groix island, Fig. 4) and Concarneau, where the nearest available tide gauges are located.

According to the simulation (left-hand portion of Fig. 6), the maximum storm surge near Gâvres exceeded $70 \mathrm{~cm}$ from about 04:20 through 05:00. The simultaneity of this maximum surge with the high tide (05:20) is the main explanation for the flood in Gâvres on this day: it led to a maximum sea level of $3.13 \mathrm{~m}$ above mean sea level at 05:10 (i.e. $55 \mathrm{~cm}$ higher compared to the highest astronomic tide).

\subsubsection{Modelling the waves}

The waves were simulated by means of the 2-D spectral model SWAN (Booij et al., 1999). To do so, two nested grids were used, with respective resolutions of 166 and $10 \mathrm{~m}$ in the coastal area (calculation areas in Fig. 2). The model was 


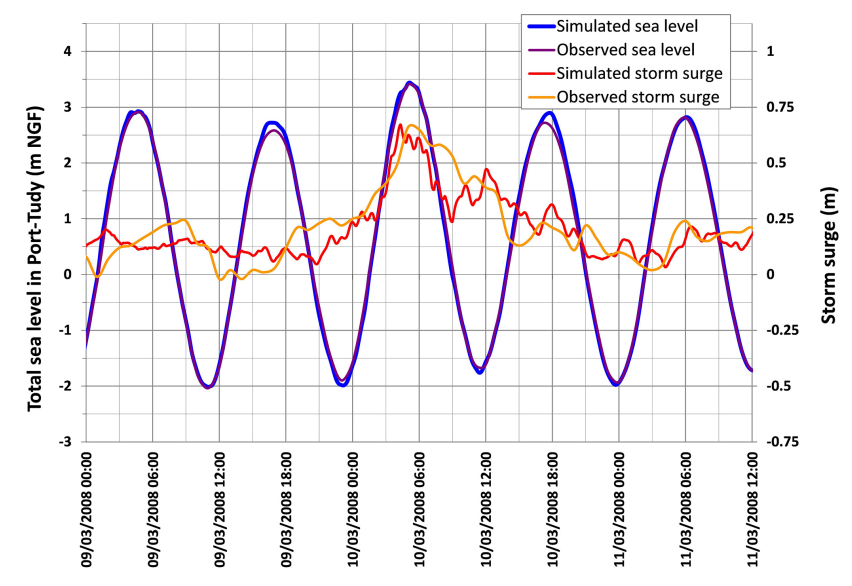

Figure 4. Validation of the total sea level (tide and storm surge) and of the storm surge simulated with MARS in Port-Tudy (observation from http://refmar.shom.fr).

forced with the waves spectra calculated in the IOWAGA project (Ardhuin et al., 2010) by the wind drawn from the CFSR-NOAA data set (Saha et al., 2010) and by the currents and sea levels from the previous simulation (MARS model). The IOWAGA simulations appear to be reliable for the Johanna storm, as illustrated in Fig. 5 for the Pierres-Noires gauge (western extremity of Brittany). The non-stationary simulation covers the period from the 9 to 11 March 2008.

This makes it possible to simulate the evolution of the waves that affected Gâvres, in terms of spectra and of overall characteristics (significant height, period, direction, setup, breaking, etc.). The results show that at the peak of the storm (about 05:00), the significant wave height reached more than $4 \mathrm{~m}$ offshore and still as high as $2 \mathrm{~m}$ on the main beach of Gâvres. The wave breaking at the storm's peak occurs just on the seaward slope of the dike, which is partially submerged depending on the sea level. An extraction of wave spectra and overall characteristics (left-hand portion of Fig. 6) was performed for the beach of Gâvres. At this point, the setup remains limited (less than $10 \mathrm{~cm}$ between 01:00 and 09:30, and nearly null, even a setdown at the storm peak, owing to the wave breaking on the dike). The analysis of the total sea level (tide, storm surge and wave setup) confirms that no overflowing appears and that the flood is caused only by wave overtopping.

The maxima of sea level and of wave heights are simultaneous (about 05:00), and the wave periods increase between 05:00 and 07:00, showing increasing wave energy and a potential for continued overtopping even if the sea level decreases. However, it is not possible to identify the time when the flooding starts and stops. For this reason, dynamic evolutions of sea level and wave characteristics need to be taken as an input in the overtopping and flood simulation.

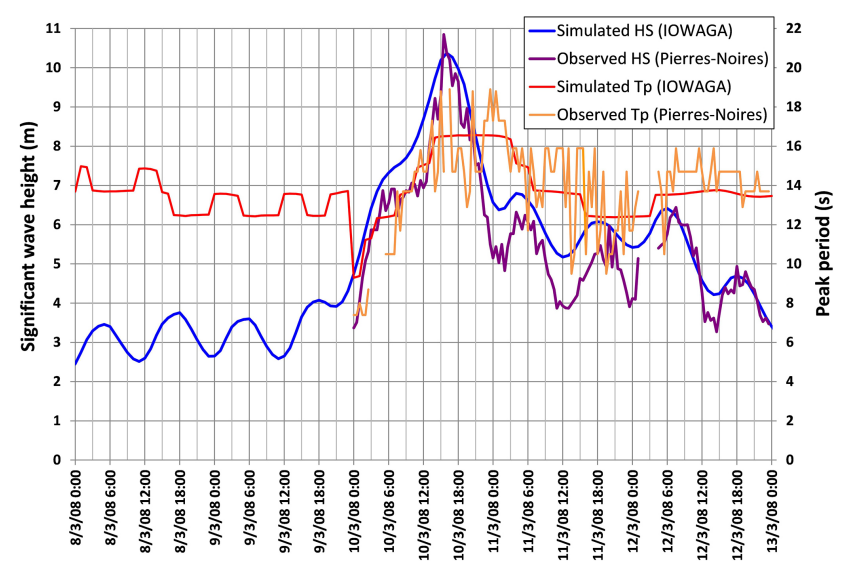

Figure 5. Validation of the wave characteristics simulated in the IOWAGA project on the Pierres-Noires gauge (observation from http://candhis.cetmef.developpement-durable.gouv.fr).

\subsection{Modelling wave overtopping and flood: model and inputs}

\subsubsection{The SURF-WB model}

The site of Gâvres lies in a macro-tidal context. Consequently, the duration of the wave overtopping is mainly controlled by the tide, coupled with the storm surge and the waves' evolutions. For this reason, the chosen model must be robust and stable enough to allow for sea-level variations of several metres during the tide.

The flooding was simulated using the time-dependent phase-resolving model SURF-WB in 2-D in view of its particular robustness. This model is based on the viscous NLSW equations, including several physical aspects with mathematical rigour: diffusion terms, friction terms, Coriolis effect, surface tension terms and wet/dry interface and dynamic time step (Marche et al., 2007). SURF-WB uses shock-capturing schemes to correctly represent the propagation of waves in the inner surf zone, and well-balanced schemes to deal with steep slopes. These specificities make SURF-WB particularly efficient for overtopping and urban flooding simulations. SURF-WB has formerly been used by Pedreros et al. (2011), in a micro-tidal context, to simulate coastal flooding in stationary conditions.

SURF-WB does not explicitly deal with energy dissipation by wave breaking, but several authors (Bonneton, 2007; Brocchini and Dodd, 2008; Kobayashi et al., 1989; Marche et al., 2007, etc.) have shown that the use of the NLSW equations with shock-capturing schemes could provide a correct representation of the waves after breaking: the energy dissipation is directly deduced from the shocks theory (Stocker, 1957) and even if the wave shapes are not reliable in the breaking zone, the results are quite similar to benchmarking results beyond the breaking zone (Tissier et al., 2012). Nevertheless, NLSW models like SURF-WB remain unable 

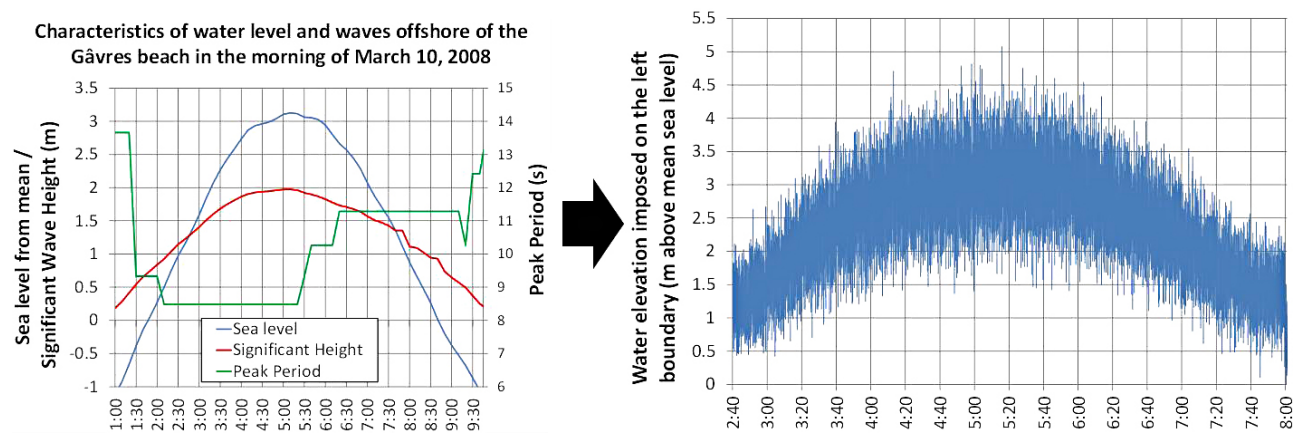

Figure 6. Evolution of the sea conditions near Gâvres during the Johanna storm (sea level from MARS simulations, significant wave height and peak period from SWAN simulations) on the left, and reconstitution of a corresponding time series of water level with the DIWASP toolbox on the right.

to simulate correctly the coastal propagation and the shoaling processes and to detect the wave breaking, like for example Boussinesq/NLSWE hybrid models (Stansby et al., 2013; Lannes and Marche, 2014; Shi et al., 2012). The consequences generally translate into a significant premature wave decrease caused by a premature breaking.

To limit this problem, the forcing of the waves in SURFWB has been placed as close as possible to the dike (about $100 \mathrm{~m}$ ): thus, the short propagation distances do not allow important consequences of the absence of dispersion terms, and at the peak of the storm (when the sea water level is high and when overtopping appears), most of the energy dissipation is controlled by the steep slope of the dike, in accordance with the results obtained with the SWAN model. Moreover, a forcing very close to the coast offers the advantage of using quite homogeneous waves perpendicular to the coast (after refraction).

\subsubsection{Forcing conditions for SURF-WB}

The forcing condition for SURF-WB was imposed on the south-eastern boundary of the calculation area (represented in Fig. 3). SURF-WB does not use any wavemaker, but calculates the incoming fluxes to correctly reconstitute a time series for water level, at shallow depth. This implies that the waves have to be homogeneous along the forcing boundary and parallel to this boundary, which strongly constrains the domain limits according to the configuration of the coast. For the application in Gâvres, as the forcing boundary is very close to the dike $(100 \mathrm{~m})$, the waves have still refracted and are quite perpendicular to the coast and homogeneous along the boundary.

The model was forced with a time series of water-levels including both sea-level variations (tide and storm surge) and waves. This time series was established by extracting the sea level (including the tide, the storm surge and the wave setup at the extraction point) and the wave spectrum from the SWAN results, with a $10 \mathrm{~min}$ time step; this was used to reconstitute, using the DIWASP tool (Johnson, 2002), a ran- dom water-level series conform with the spectra (condition varying every $10 \mathrm{~min}$ ), with a time step of $0.1 \mathrm{~s}$. The time series generated covers from 02:40 to 08:00, to be sure to include the onset and the end of the overtopping. It is represented on the right-hand portion of Fig. 6.

This whole time series was imposed on the offshore boundary of the calculation area, and SURF-WB then calculated both wave propagation, overtopping and flood dynamics. Using a single processor, the time computation is such that $5.3 \mathrm{~h}$ (with a time step of $0.043 \mathrm{~s}$ ) is simulated in 8.5 days.

\subsubsection{The Digital Elevation Model}

To simulate the flooding at a very high resolution, precise data are needed for topography and land use. This type of data is provided thanks to recent advances in airborne scanner laser altimetry (LiDAR), which is available on the studied site. Current processing makes it possible to obtain a precise and reliable DTM, but that lacks data on land use: buildings, walls, vegetation, etc. It is therefore necessary to build a DEM by extracting, from raw data, the largest possible amount of information about all the elements that interfere with the flooding, especially buildings and garden walls. The resolution of this DEM has to be sharp enough to correctly represent the water flows in the urban area, and assess all the potential pathways for water (Fewtrell, 2011).

For Gâvres, the LiDAR data characterization in terms of land use was procured semi-automatically with LasTools software (Hug et al., 2004), completed by a field survey. The DEM interpolation was performed with ArcGIS, with a $1 \mathrm{~m}$ resolution, and includes all buildings and walls in the studied area. Ultimately, the $1 \mathrm{~m}$ resolution grid numbers 607 nodes (from south-east to north-west) by 663 nodes (from northeast to south-west). It is important to note that, as the collapse time of the wall over the dike is still unknown, this wall has been considered destroyed since the beginning of the simulation. Particular care has been taken with the representation of the dike and this wall, insofar as their topog- 

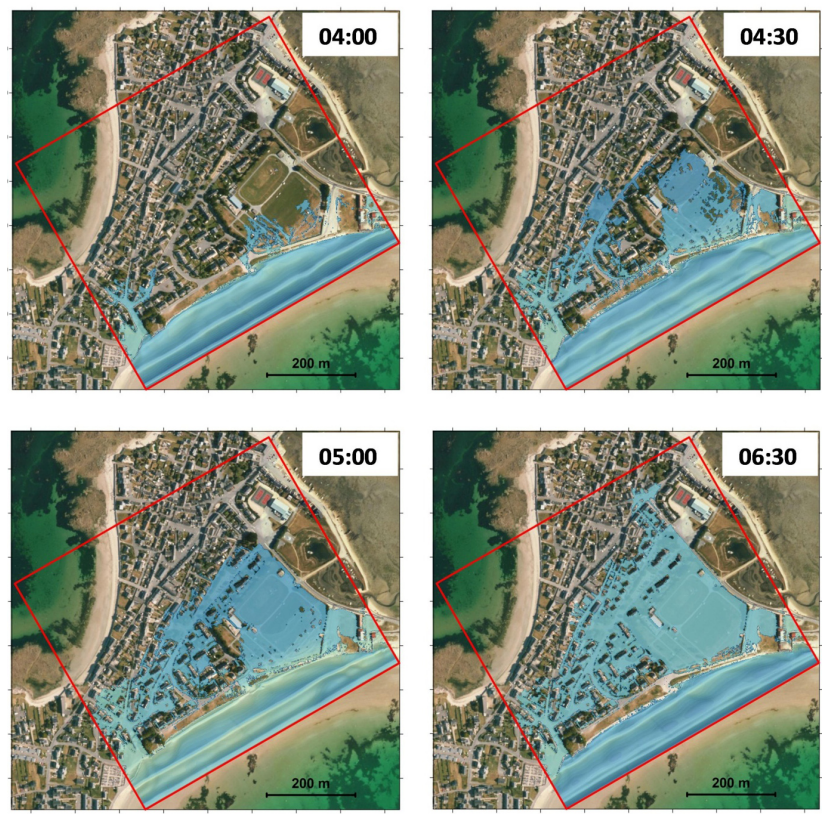

Figure 7. Snapshots of the SURF-WB simulation of overtopping and flooding: Situation at 04:00, 04:30, 05:00 and 06:30 (UTC).

raphy strongly constrains the overtopping volume of water. This DEM is represented in Fig. 3.

\subsubsection{The roughness map}

Given the flooding configuration in Gâvres (filling of a topographic depression), the effect of the soil roughness is quite limited (essentially impacting the flow speeds), aside from the land-sea interface (dike and walls). It therefore was decided to distinguish only the natural sea floor (Manning coefficient of $0.025 \mathrm{~s} \mathrm{~m}^{-1 / 3}$, typical for gravels and natural channels), the concrete areas (dike and urban areas including buildings, Manning coefficient of $0.014 \mathrm{~s} \mathrm{~m}^{-1 / 3}$ ) and the football pitch (Manning coefficient of $0.07 \mathrm{~s} \mathrm{~m}^{-1 / 3}$, typical for grass in built-up areas).

\section{Model results: validation and analysis}

\subsection{Validation}

The elements of validation are mainly the water depth measurements of Cariolet (2010), the water stagnation area reported by Le Cornec and Peeters (2008), the locations of flooded houses and reports about the flood chronology.

\subsubsection{Overtopping sectors}

According to the simulation, most of the wave overtopping occurred in the "Beach street" and on the eastern part of the "Main Beach" dike, where the wall was destroyed. Between these two sectors, the overtopping remained rare and

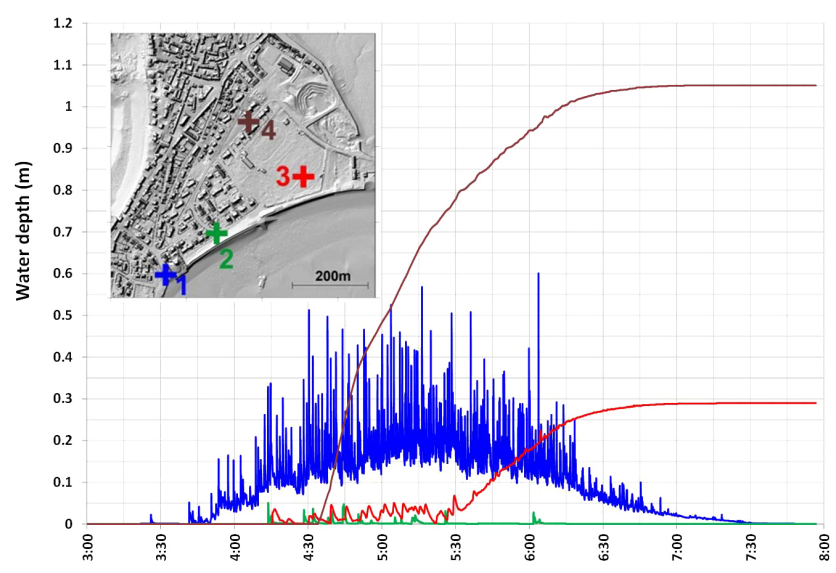

Figure 8. Evolution of the water depth on four numerical gauges during the SURF-WB simulation on the DEM.

very limited. This can be observed in Fig. 8 which represents the water depth of four numerical gauges in Gâvres: frequent wave overtopping can be underlined in Gauges 1 ("Beach street") and 3 ("Main Beach" dike), whereas overtopping remains sporadic and brief in Gauge 2. This is coherent with Cariolet (2010), who did not identify this sector as an overtopping zone (Fig. 10, top part).

\subsubsection{Extent of flooding}

The water stagnation area indicated by the municipality lies totally within the flooded area indicated by the simulation. When compared to insured damages, the results are very coherent too, with all of the houses concerned being included in the simulated flooded area (aside from the two northernmost points, supposed to have been affected by only a little water in the underground level, possibly due to waves coming directly from the north). A few houses west of the area, as well as others in the northernmost sector, were not indicated as having incurred damages, although the simulation indicates that these areas could be affected by several tens of centimetres of water.

\subsubsection{Water depths}

The 23 measurements made by Cariolet (2010) were performed after the event, mainly on the strength of marks left on the walls or the ground; it is consequently likely that these levels do not represent the maximum water depth, but the levels at which the water stagnated. Moreover, they are quite difficult to interpret insofar as they are expressed directly in water depth, with no reference made to the point where it was measured (microtopography, interior or exterior of a house, etc.). These measurements also differ locally from the municipality's data and from the topography, in particular near the square located in the western part of the football pitch. For 


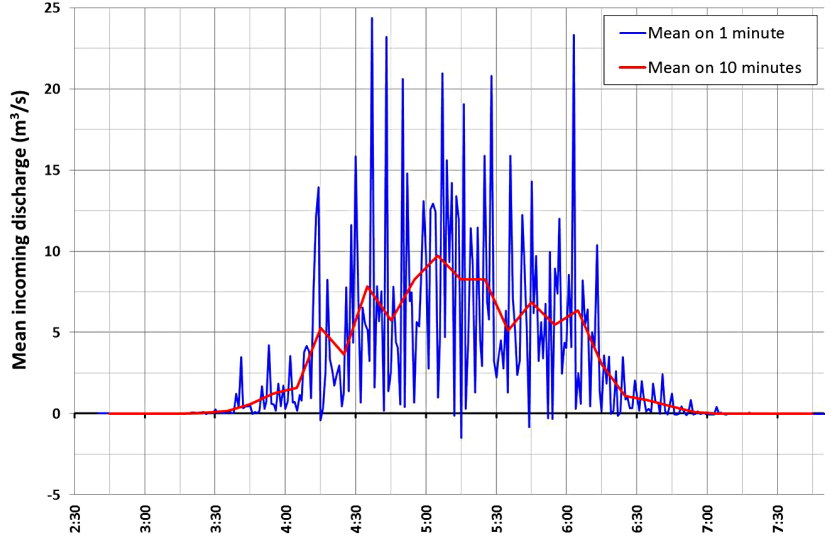

Figure 9. Evolution of the overtopping flow rate versus time (estimated at the time steps of 1 and $10 \mathrm{~min}$ ) during the SURF-WB simulation.

these reasons, the measurements obtained by Cariolet (2010) can be used to qualitatively validate the simulation.

Compared to the measurements (Fig. 10), the maximum or final water depths from the simulation are globally coherent. Taking into account the aforementioned limits, calculated maximum water depths are compatible with the measured values for $50 \%$ of the points. The differences in water depth do not exceed $10 \mathrm{~cm}$ for $60 \%$ of cases, and $15 \mathrm{~cm}$ for $75 \%$. However, a couple of points in the middle of the area seem to be contradictory compared to the simulation, reports (damage, stagnation area) and topography. This problem can be ascribed to measurement errors and other sources of uncertainties.

\subsubsection{Flood chronology}

The report quoted by Le Cornec and Peeters (2008) was given by the resident of a house located on the "Parc des Sports" street, near Gauge 4 (Fig. 8). It indicates that there was no water until 04:50, and that the water first arrived from the south via the street at 05:00 and from the football pitch at 05:10. The level rose to reach $65 \mathrm{~cm}$ inside the house between 05:30 and 05:45. A photograph taken at 06:16 shows that the level rose further compared to one taken at 05:46. Compared to the water depth simulated on Gauge 4 (Fig. 8), this report is virtually compatible with the simulation, although in the simulation the onset of the flood is slightly earlier (around 04:40), but its subsequent progression is very close to the report. In the simulation, the water arrives simultaneously from the street and the football pitch; it should be borne in mind that the simulation has considered that the wall on the dike was destroyed from the start of the simulation, which could explain this discrepancy.

Finally, the simulation proves to be quite coherent with the available validation data: the extent of the flooded area is consistent with the observation, the maximum simulated water depths are comparable to the measurements and the
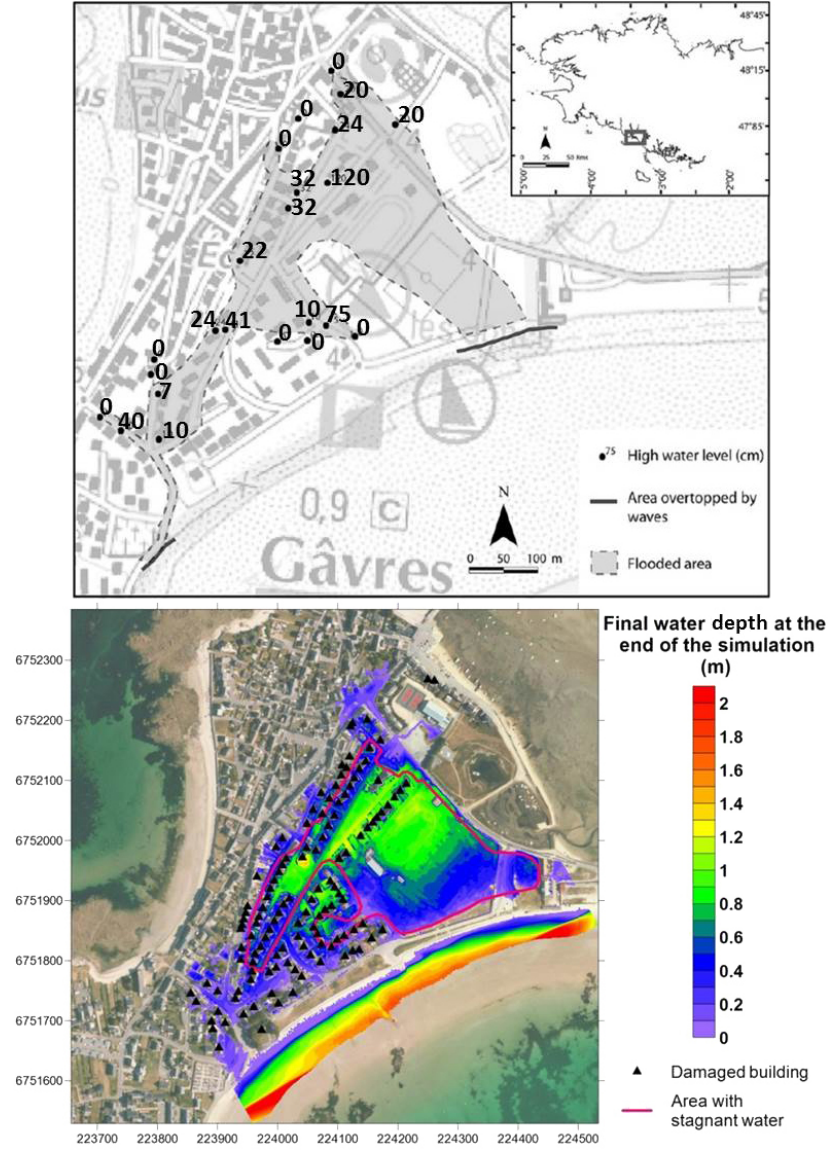

Figure 10. Above: measurements of maximum water depths (modified from Cariolet, 2010); below: final water depth at the end of the SURF-WB simulation and reported flooded buildings and stagnation area according to the municipality (from the Gâvres municipality and Le Cornec and Peeters, 2008).

chronology seems to be quite correct in the light of available reports.

\subsection{Analysis: flooding dynamics, water levels and currents}

The results obtained by simulation allow us to have access, for each point of the calculation grid and for each time step, to the water levels and flows both at sea and inland: the overtopping and flooding can therefore be described in detail for each wave, as illustrated in Fig. 7.

The results of the simulation show that the wave overtopping starts at about 03:20 in the southern portion of the area ("Beach street") and at about 03:40 on the dike per se. The overtopping continues to be significant until about 06:40, with a maximum occurring approximately just after 05:00. After 07:00, the water flow rate becomes slightly negative because the water tends to recede into the sea via the access to sea in "Beach street". This is illustrated in Fig. 9, which depicts the evolution of the overtopping water flow rate ver- 

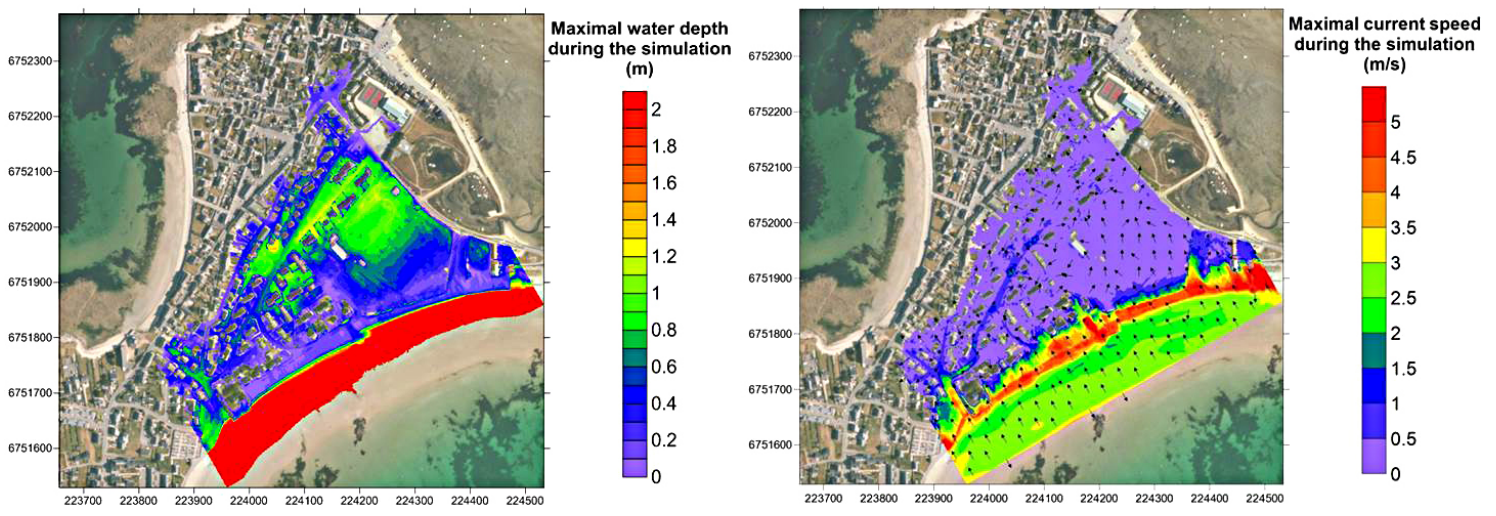

Figure 11. Maximum water depths (left) and currents (right) obtained inland during the SURF-WB simulation on the DEM (with explicit representation of the buildings).

sus time (estimated with time steps of 1 and $10 \mathrm{~min}$ to smooth the wave effects). Finally, at the end of the simulation (at about 08:00), the flooded area corresponds to a stable stretch of water inland (Fig. 10), with a water level very close to the maximum water level during the simulation (Fig. 11).

The analysis of numerical gauges implanted in the simulation allows the mechanisms of the flood to be identified (Fig. 8):

- Gauge 1 ("Beach street"): the shape of the water depth curve can be explained by a local overflowing not detected by coastal MARS and SWAN simulations due to coarse resolutions: after a couple of instances of wave overtopping, the sea level reached this topographic level at 03:50; the waves could then come directly inland, and were perceptible on the gauge; the level subsequently decreased with the tide, with overflow ending at about 07:30, and no water remained at the end of the simulation.

- Gauge 2 (located behind the dike, south of the football pitch): this gauge indicates only sporadic transiting water between 04:15 and 06:00, with no accumulation; a few waves overtopped the dike at this level, and this water progressively flowed toward the lowest areas, as illustrated in Fig. 7.

- Gauge 3 (located behind the dike, at the edge of the football pitch, where the wall over the dike collapsed): as for Gauge 2, only transiting water was observed from 04:15 to $05: 30$ (but more intensive), but from 05:30 to 06:45 the global level had risen, linked to the filling of the topographic depression constituted by the football pitch (Fig. 7); few wave arrivals could then be individually detected, and the water stabilized around $0.29 \mathrm{~m}$.

- Gauge 4 ("Parc des Sports" street; practically at the bottom of the topographic depression): at this point, no wave arrivals were detectable because water arrived by flowing from the streets and from the football pitch. The rate at which the depression filled varied, depending on the overtopping waves and on the link between water level and shape of the depression (the rate of fill slowed after 04:50 because the volume of water input required to elevate the water surface increased considerably). The stabilization of the water level around 06:45 shows the presence of stagnant water inland.

The comparison between the simulated maximum water depths (Fig. 11) and those obtained by Le Cornec and Peeters (2008) shows that the maximum water depths obtained here seem to be quite a bit smaller, but more consistent with the available observations. In terms of maximum current speeds (Fig. 11), the dynamic simulation of each wave overtopping highlights the existence of areas just behind the dike where velocities are high ( 3 to $5 \mathrm{~m} \mathrm{~s}^{-1}$ on several tens of metres behind the dike). The approach based on imposing mean overtopping discharges (with a smoothing effect of the individuals waves, like in Fig. 9) leads to significantly smaller velocities, about $1.5 \mathrm{~m} \mathrm{~s}^{-1}$ according to Le Cornec and Schoorens (2007) who estimated overtopping using EurOtop in Gâvres for very similar events.

\subsection{Discussion: sensitivity to the description of buildings and limitations of the method}

\subsubsection{Urban representation}

The same flood simulation was conducted directly on the DTM, thus without taking the buildings and the walls explicitly into account. The urbanized area has been represented through an increased soil roughness (Manning coefficient of $0.1 \mathrm{~s} \mathrm{~m}^{-1 / 3}$ ), and the dike and the football pitch are the only remaining unmodified elements (presence of the wall on the dike where it didn't collapse, Manning coefficients of $0.014 \mathrm{~s} \mathrm{~m}^{-1 / 3}$ for concrete and $0.07 \mathrm{~s} \mathrm{~m}^{-1 / 3}$ for grass). The forcing condition is exactly the same as for the previous simulation (sea level and waves). 


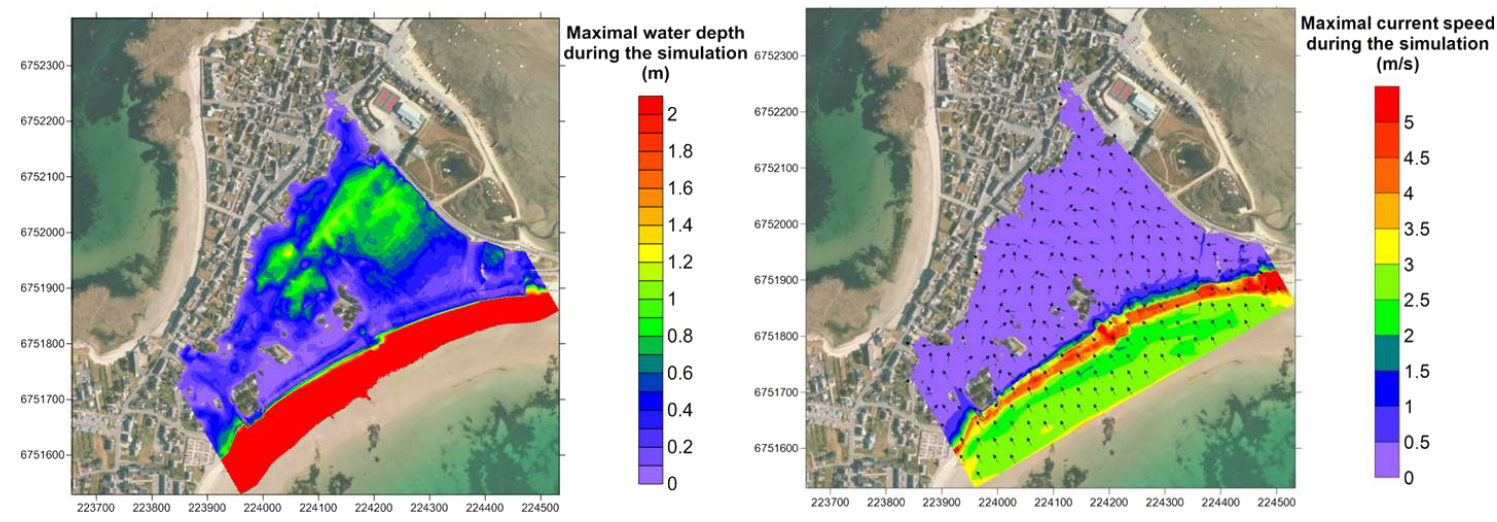

Figure 12. Maximum water depths (left) and currents (right) obtained inland during the SURF-WB simulation on the DTM (without explicit representation of the buildings).

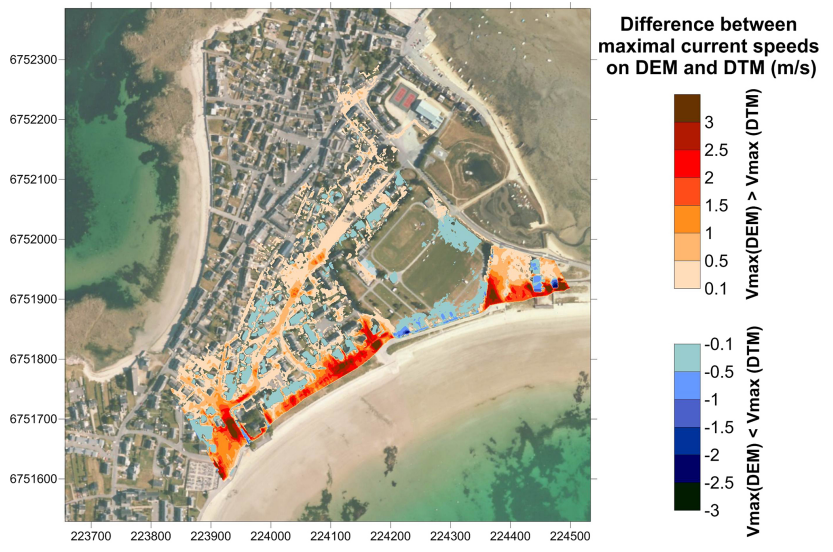

Figure 13. Difference between the maximum current speeds obtained inland during the SURF-WB simulations, with and without an explicit representation of the buildings $\left(V_{\max } \mathrm{DEM}^{-} V_{\max } \mathrm{DTM}\right)$.

The results obtained (Fig. 12) show that, for the studied case of Gâvres where the flooding process remains quite slow (only overtopping and water flowing and filling a topographic depression), this type of representation of urbanization leads to results that are very similar to those obtained with a DEM (represented in Fig. 11). This is particularly true for the extension of the flooded area and for the maximum water depths.

Some significant differences, however, do appear between the two configurations in terms of flood dynamics. Indeed, as the flow speeds in the simulations are directly controlled by soil roughness, the flows are notably slower with an urbanized area represented by a high Manning coefficient than they are with an explicit representation of buildings, which can have significant consequences for hazard analysis in urban areas. A comparison of the maximum calculated flow speeds in the two configurations (Fig. 13) shows that the differences are concentrated mainly on three sectors: the buildings (because they remain dry with the DEM); the main streets (here the "Parc des Sports" street), where an increased roughness leads to a significant underestimation of the current speeds (here from 1 to $2.5 \mathrm{~m} \mathrm{~s}^{-1}$ with the DEM to 0.2 to $0.3 \mathrm{~m} \mathrm{~s}^{-1}$ with an urban area represented by an increased roughness); and the seaside, where the high velocity area is directly limited by the identification of the urban area boundary and the associated transition in roughness coefficients. These effects should have been limited by increasing the roughness only in the building footprints and street walls (instead of the whole urban area), in order to allow high velocity flows caused by the canalizing in the streets. Nevertheless, the simulations realized by Syme (2008) show that representing a building by an increased roughness instead of a block in the topography leads to local differences in the flow velocities (especially an underestimation of the upstream slowdown and an overestimation of the slowdown along sideways walls).

Finally, this comparison shows that studying flooding in an urban area implies necessarily a realistic representation of the buildings in order to allow a precise interpretation of the results.

\subsubsection{Limitations of the method}

The use of time-dependent phase resolving models remains recent, and currently quite difficult to implement because of a certain number of limitations and difficulties.

The main limitations, directly linked to the numerical models, involve the physical processes taken into account; indeed, if wave breaking is now increasingly integrated into this type of model (especially with Boussinesq/NLSW hybrid models), the integration of erosion and breaching in dunes or dikes continues to date to be very problematical, despite the fact that these phenomena constitute a major explanation for many of coastal floods. In our simulation, the main hypothesis concerns the timing of the collapsed wall on the dike: the wall has been considered absent from the start of the simulation. To qualify the impact of this hypothesis, a complementary simulation has been realized with the other 
extreme hypothesis, i.e. that the wall remained intact during the storm. Results show a limited impact on this case: overtopping is locally reduced over the dike, leading to a flooded area slightly modified, but with water depths reduced to about $16 \mathrm{~cm}$ around the football pitch.

The numerical approaches with respect to physical phenomena can constitute another limitation for these models, mainly concerning the forcing conditions, which need to be reliable enough to correctly generate the waves, with a robustness of the model that is sufficient to cope with general sea level evolution throughout a long simulation under nonstationary conditions.

Moreover, simulating overtopping and flooding at a very high resolution implies using very short time steps (largely higher than $10-20 \mathrm{~Hz}$ ), which result in long calculation times, especially if the model used is not parallelized.

Finally, despite its efficiency, this type of simulation is still quite rare and expensive, due to the difficulty in implementing the time-dependent phase-resolving model (optimization of the link between model limits and site configuration) and to the calculation time. For this reason, it remains currently restricted to urban areas with large assets or in the framework of research projects.

\section{Conclusions}

The goal of this study was to propose and apply a methodology which could simulate the whole complexity of the problem of a coastal flood by wave overtopping in an urban area. The proposed method relies on simulations on regional to local scales to calculate the evolution of sea level (tide and storm surge) and of wave characteristics, which are used to force a time-dependent phase-resolving model, using wellbalanced shock-capturing schemes, in order to simulate wave overtopping. Moreover, the choice of such a model combined with the use of a very high resolution DEM (including buildings and walls) makes it possible to simulate at the same time the flood propagation in an urban area.

Finally, this approach enables the most important parameters of the phenomena to be taken into account: time evolution of sea level and wave characteristics (to simulate dynamically the time evolution of the event), spatial and temporal distribution of the overtopping and flood simulation in an urban area with explicit buildings.

This methodology has been applied to the site of Gâvres, flooded during the Johanna storm in 2008. The SURF-WB model allowed this event to be reconstituted with a satisfactory level of precision compared to the available observations (flooded area, chronology, maximum water level).

A comparison of these results with a similar simulation using a more classical approach (no explicit buildings and walls, but an increased roughness for the whole urban area) showed the advantage of an explicit representation of buildings and walls for hazard assessment in urban areas: even if, in the particular case of Gâvres, the water level is not modified significantly by the simpler approach, the flood dynamics and the current speeds are underestimated considerably in the streets and on the seafront when the effects of buildings are not explicitly integrated.

This type of simulation may, in the years to come, be increasingly called upon, thanks to the recent and future improvements of time-dependent phase-resolving models. However, the use of these models continues at present to be quite difficult due to a certain number of limitations and difficulties, mainly involved with physical processes (wave breaking, erosion and breaching, etc.), forcing conditions (wave generator, etc.) and computing time. For instance, the use of Boussinesq/NLSW hybrid models should allow for a better management of wave breaking, allowing for the forcing of the model before the shoaling area. Indeed, the constant progress being made in computing and numerical modelling should in fruition enable these limits to be overcome, thereby opening the way towards a generalization of these applications for operational studies.

Acknowledgements. This study was carried out within the JOHANNA project, supported by the MAIF Foundation for Risk Prevention Research and the BRGM, and an applied research program supported by the French ministry in charge of the environment and the BRGM. The authors would like to thank IFREMER, for the availability of the MARS model, and the municipality of Gâvres and DDTM (Direction Départementale des Territoires et de la Mer) of Morbihan for providing data (respectively the list of flooded houses and the LiDAR data). They likewise are indebted to the French institutions that make several sets of necessary data publicly available: SHOM for the sea-level measurements REFMAR, CEREMA for the wave measurements of the Candhis database, and Fabrice Ardhuin for the simulations conducted in the IOWAGA project. Finally, the authors thank Déborah Idier for her judicious advice, Jody Mohammadioun for English language verification and Maurice McCabe for his helpful comments and suggestions.

Edited by: I. Didenkulova

Reviewed by: M. Mccabe and one anonymous referee

\section{References}

André, C.: Analyse des dommages liés aux submersions marines et évaluation des coûts induits aux habitations à partir de données d'assurance, perspectives apportées par les tempêtes Johanna (2008) et Xynthia (2010), PhD Thesis of the University of Western Brittany, Brest, 2013 (in French).

André, C., Monfort, D., Bouzit, M., and Vinchon, C.: Contribution of insurance data to cost assessment of coastal flood damage to residential buildings: insights gained from Johanna (2008) and Xynthia (2010) storm events, Nat. Hazards Earth Syst. Sci., 13, 2003-2012, doi:10.5194/nhess-13-2003-2013, 2013.

Ardhuin, F., Rogers, A., Babanin, A., Filipot, J. F., Magne, R., Roland, R., Westhuysen, A. V. D., Queffleulou, P., Lefevre, L., 
Aouf, L., and Collard, F.: Semi-empirical dissipation source functions for ocean waves: Part I, definition, calibration and validation. J. Phys. Oceanogr., 40, 1917-1941, 2010.

Bates, P. D., Horitt, M. S., and Fewtrell, T. J.: A simple inertial formulation of the shallow water equations for efficient two dimensional flood inundation modeling, J. Hydrol., 387, 33-45, 2010.

Bates, P. D. and De Roo, A. P. J.: A simple raster-based model for flood inundation simulation, J. Hydrol., 236, 54-77, 2000.

Bates, P. D., Dawson, R. J., Hall, J. W., Horritt, M. S., Nicholls, R. J., Wicks, J., and Hassan, M. A. A. M.: Simplified twodimensional numerical modeling of coastal flooding and example applications, Coastal Eng., 52, 793-810, 2005.

Begnudelli, L., Sanders, B. F., and Bradford, S. F.: An adaptive Godunov-based model for flood simulation, J. Hydraul. Eng., 134, 714-725, 2008

Bonneton, P.: Modelling of periodic wave transformation in the inner surf zone, Ocean Eng., 34, 1459-1471, 2007.

Bonneton, P., Chazel, F., Lannes, D., Marche, F., and Tissier, M.: A splitting approach for the fully nonlinear and weakly dispersive Green-Naghdi model, J. Comput. Phys., 230, 1479-1498, 2011.

Booij, N., Ris, R. C., and Holthuijsen, L. H.: A third-generation wave model for coastal regions, Part I, Model description and validation, J. Geophys. Res., 104, 7649-7666, 1999.

Breilh, J. F., Chaumillon, E., Bertin, X., and Gravelle, M.: Assessment of static flood modeling techniques: application to contrasting marshes flooded during Xynthia (western France), Nat. Hazards Earth Syst. Sci., 13, 1595-1612, doi:10.5194/nhess-131595-2013, 2013.

Brocchini, M. and Dodd, N.: Nonlinear shallow water equation modeling for coastal engineering, J. Waterway, Port, Coastal. Ocean Eng., 134, 104-120, 2008.

Cariolet, J.-M.: Use of high water marks and eyewitness accounts to delineate flooded coastal areas: The case of Storm Johanna (10 March 2008) in Brittany, France, Ocean Coastal Manage., 53, 679-690, 2010.

Cariolet, J.-M.: Inondation des côtes basses et risques associés en Bretagne, PhD Thesis of the University of Western Brittany, Brest, 2011 (in French).

Cariolet, J.-M., Costa, S., Caspar, R., Ardhuin, F., Magne, R., and Goasguen, G.: Atmospheric and marine aspects of the 10th of March 2008 storm in Atlantic and in the Channel, Norois, 215, 11-31, doi:10.4000/norois.3242, 2010 (in French).

Fewtrell, T. J., Duncan, A., Sampson, C. C., Neal, J. C., and Bates, P. D.: Benchmarking urban flood models of varying complexity and scale using high resolution terrestrial LiDAR data, Phys. Chem. Earth, 36, 281-291, 2011.

Fortunato, A. B., Rodrigues, M., Dias, J. M., Lopes, C., and Oliveira, A.: Generating inundation maps for a coastal lagoon: A case study in the Ria de Aveiro (Portugal), Ocean Eng., 64, 60-71, 2013.

Gallegos, H. A., Schubert, J. E., and Sanders, B. F.: Twodimensional, high-resolution modeling of urban dam-break flooding: A case study of Balwin Hills, California, Adv. Water Resour., 32, 1323-1335, 2009.

Gallien, T. W., Schubert, J. E., and Sanders, B. F.: Predicting tidal flooding of urbanized embayments: A modeling framework and data requirements, Coastal Eng., 58, 567-577, 2011.
Hug, C., Krzystek, P., and Fuchsc, W.: Advanced LiDAR data processing with LasTools, XXth ISPRS Congress, 12-23, July 2004, Istanbul, Turkey, 2004.

Johnson, D.: DIWASP: DIrectional WAve SPectra Toolbox, Version 1.1: User Manual, Research Report No: WP 1601 DJ (V1.1), Coastal Oceanography Group Centre for Water Research, University of Western Australia, Perth, 2002.

Kobayashi, N., Silva, G. D., and Watson, K.: Wave transformation and swash oscillation on gentle and steep slopes, J. Geophys. Res., 94, 951-966, 1989.

Lannes, D. and Marche, F.: A new class of fully nonlinear and weakly dispersive Green-Naghdi models for efficient 2D simulations, J. Comput. Phys., 282, 238-268, 2014.

Lazure, P. and Dumas, F.: An external-internal mode coupling for a 3D hydrodynamical model for applications at regional scale (MARS), Adv. Water Resour., 31, 233-250, doi:10.1016/j.advwatres.2007.06.010, 2008.

Le Cornec, E. and Schoorens, G.: Etude de l'aléa submersion marine sur le site de la Grande Plage de Gâvres, Rapport d'étude GEOS-DHI, 2007 (in French).

Le Cornec, E. and Peeters, P.: Simulation de la tempête du 10 mars 2008 sur le site de la Grande Plage de Gâvres, Rapport d'étude GEOS-DHI, 2008 (in French).

Le Roy, R. and Simon, B.: Réalisation et validation d'un modèle de marée en Manche et dans le Golfe de Gascogne. Application à la réalisation d'un nouveau programme de réduction des sondages bathymétriques, EPSHOM (Etablissement Principal du Service Hydrographique et Océanographique de la Marine, Brest), Technical report no 002/03, 2003 (in French).

Lynett, P. J.: Nearshore wave modeling with high-order Boussinesqtype equations, ASCE Journal of Waterway, Port, Coastal Ocean Eng., 132, 348-357, 2006.

Lynett, P. J., Melby, J. A., and Kim, D. H.: An application of Boussinesq modeling to Hurricane wave overtopping and inundation, Ocean Eng., 37, 135-153, 2010.

Marche, F., Bonneton, P., Fabrie, P., and Seguin, N.: Evaluation of well-balanced bore-capturing schemes for $2 \mathrm{~d}$ wetting and drying processes, Int. J. Numerical Methods Fluids, 53, 867-894, 2007.

McCabe, M. V., Stansby, P. K., and Apsley, D. D.: Random wave runup and overtopping a steep sea wall: Shallow-water and Boussinesq modelling with generalised breaking and wall impact algorithms validated against laboratory and field measurements, Coastal Eng., 74, 33-49, 2013.

Neal, J. C., Bates, P. D., Fewtrell, T. J., Hunter, N. M., Wilson, M. D., and Horritt, M. S.: Distributed whole city water level measurements from the Carlisle 2005 urban flood event and comparison with hydraulic model simulations, J. Hydrol., 368, 42-55, 2009.

Pedreros, R., Vinchon, C., Lecacheux, S., Delvallée, E., Balouin, Y., Garcin, M., Krien, Y., Le Cozannet, G., Poisson, B., Thiebot, J., Bonneton, P., and Marche, F.: Multi models approach to assess coastal exposure to marine inundation within a global change context, Poster, EGU (European Geosciences Union) General Assembly, Wien, 3-8 April 2011, 2011.

Peeters, P., Schoorens, J., Lecornec, E., Michard, B., and Lechat, M.: Définition de l'aléa submersion marine sur le site de la Grande Plage de Gâvres (Morbihan), La Houille Blanche, 12009, 45-51, doi:10.1051/lhb:2009004, 2009 (in French). 
Pullen, T., Allsop, N. W. H., Bruce, T., Kortenhaus, A., Schüttrumpf, H., and van des Meer, J. W.: EurOtop. Wave overtopping of sea defences and related structures: Assessment manual, Archive for Research and Technology on the North Sea and Baltic coast, available at: www.overtopping-manual.com, 2007.

Saha, S., Moorthi, S., Pan, H.-L., Wu, X., Wang, J., Nadiga, S., Tripp, P., Kistler, R., Woollen, J., Behringer, D., Liu, H., Stokes, D., Grumbine, R., Gayno, G., Wang, J., Hou, Y.-T., Chuang, H.Y., Juang, H.-M. H., Sela, J., Iredell, M., Treadon, R., Kleist, D., Van Delst, P., Keyser, D., Derber, J., Ek, M., Meng, J., Wei, H., Yang, R., Lord, S., Van Den Dool, H., Kumar, A., Wang, W., Long, C., Chelliah, M., Xue, Y., Huang, B., Schemm, J.-K., Ebisuzaki, W., Lin, R., Xie, P., Chen, M., Zhou, S., Higgins, W., Zou, C.-Z., Liu, Q., Chen, Y., Han, Y., Cucurull, L., Reynolds, R. W., Rutledge, G., and Goldberg, M.: The NCEP Climate Forecast System Reanalysis, B. Am. Meteor. Soc., 91, 1015-1057, doi:10.1175/2010BAMS3001.1, 2010.

Schubert, J. E. and Sanders, B. F.: Building treatments for urban flood inundation models and implications for predictive skill and modeling efficiency, Adv. Water Resour., 41, 49-64, 2012.

Schubert, J. E., Sanders, B. F., Smith, M. J., and Wright, N. G.: Unstructured mesh generation and landcover-based resistance for hydrodynamic modeling of urban flooding, Adv. Water Resour., 31, 1603-1621, 2008.

Shi, F., Kirby, J. T., Harris, J. C., Geiman, J. D., and Grilli, S. T.: A high-order adaptive time-stepping TVD solver for Boussinesq modeling of breaking waves and coastal inundation, Ocean Modell., 43-44, 36-51, doi:10.1016/j.ocemod.2011.12.004, 2012.

SHOM: Références Altimétriques Maritimes, Ports de France métropolitaine et d'outre-mer. Cotes du zéro hydrographique et niveaux caractéristiques de la marée, Service Hydrographique et Océanographique de la Marine (Brest), ISBN 978-2-11-0972866, 2012 (in French).
Smith, R. A. E., Bates, P. D., and Hayes, C.: Evaluation of coastal flood inundation model using hard and soft data, Environ. Modell. Softw., 30, 35-46, 2012.

Stansby, P., Chini, N., Apsley, D., Borthwick, A., Bricheno, L., Horillo-Caraballo, J., McCabe, M., Reeve, D., Rogers, B., Saulter, A., Scott, A., Wilson, C., Wolf, J., and Yan, K.: An integrated model system for coastal flood prediction with a case history for Walcott, UK, on 9th November 2007, J. Flood Risk Manage., 6, 229-252, doi:10.1111/jfr3.12001, 2013.

Stocker, J. J.: Water Waves - The Mathematical Theory With Applications, Interscience Publishers, Inc., New York, 1957.

Syme, W. J.: Flooding in urban areas - 2D modelling approaches for buildings \& fences, 9th National Conference on Hydraulics in Water Engineering, Engineers Australia, Darwin, 2008.

Tissier, M., Bonneton, P., Marche, F., Chazel, F., and Lannes, D.: A new approach to handle wave breaking in fully non-linear Boussinesq models, Coastal Eng., 67, 54-66, doi:10.1016/j.coastaleng.2012.04.004, 2012.

Tonelli, M. and Petti, M.: Numerical simulation of wave overtopping at coastal dikes and low-crested structures by means of a shock-capturing Boussinesq model, Coastal Eng., 79, 75-88, 2013.

Torres-Freyermuth, A., Mariño-Tapia, I., Coronado, C., Salles, P., Medellín, G., Pedrozo-Acuña, A., Silva, R., Candela, J., and Iglesias-Prieto, R.: Wave-induced extreme water levels in the Puerto Morelos fringing reef lagoon, Nat. Hazards Earth Syst. Sci., 12, 3765-3773, doi:10.5194/nhess-12-3765-2012, 2012.

Zijlema, M., Stelling, G., and Smit, P.: SWASH: An operational public domain code for simulating wave fields and rapidly varied flows in coastal waters, Coastal Eng., 58, 992-1012, doi:10.1016/j.coastaleng.2011.05.015, 2011. 